\title{
Identification of Herb Pairs in Esophageal Cancer
}

\author{
Yu-Mei Cai ${ }^{a}$ Hui Zhu ${ }^{a, b}$ Jing-Xiu Niu ${ }^{a, b}$ Lin Bing $^{a, b} \quad$ Zhen Sun $^{a}$ Wen-Hua Zhang ${ }^{a, b}$ \\ Jian-Zi Ying ${ }^{a}$ Xiao Dong Yin ${ }^{a}$ Jing $\mathrm{Li}^{a} \quad$ Yan Pang $^{\mathrm{a}, \mathrm{b}} \quad$ Jia-Li Li ${ }^{\mathrm{a}, \mathrm{b}}$ \\ ${ }^{a}$ Department of Oncology, Tianjin Union Medical Center, Tianjin, China; \\ ${ }^{b}$ Tianjin Institute of Chinese Integrative Medicine of Oncology, Tianjin, China
}

\section{Keywords}

Cluster analysis - Association rules - Overall survival . Chinese herbal medicine - Esophageal cancer

\section{Summary}

Background: Chinese herbal medicine (CHM) is used widely to treat various diseases, including cancer. However, effective herb pairs for treating specific cancer types have so far not been identified. Here, we aimed to calculate the survival benefits of herb pairs by cluster analysis, association rules, and survival evaluation in patients with esophageal cancer (EC) treated with CHM. Patients and Methods: 59 patients with EC who received 176 prescriptions including 178 types of herbs were enrolled into the study. The herb pairs were identified by both cluster analysis and association rules. Overall survival (OS) was estimated by the Kaplan-Meier method. Results: Eight groups of herb pairs were identified by cluster analysis, and 4 groups of herb pairs were identified by association rules. Of these, 3 groups of herb pairs were identified by both methods. OS estimation showed that the pair of chicken gizzard-membrane/Astragalus was associated with improved survival in patients with EC treated with CHM. Conclusion: Patients who received prescriptions containing the pair of chicken gizzardmembrane and Astragalus had improved OS compared with patients who received prescriptions lacking this pair.

(c) 2017 The Author(s). Published by S. Karger GmbH, Freiburg

\section{Schlüsselwörter}

Cluster-Analyse - Assoziationsregeln · Gesamtüberleben . Chinesische Phytomedizin . Ösophaguskarzinom

\section{Zusammenfassung}

Hintergrund: Die chinesische Kräutermedizin (CHM) wird vielfach genutzt, um verschiedenste Krankheiten einschließlich Krebs zu behandeln. Jedoch sind bisher noch keine effektiven Kräuterpaare zur Behandlung spezifischer Krebsarten identifiziert worden. Ziel dieser Studie war es, den Gewinn an Überlebenszeit durch Kräuterpaare zu kalkulieren, anhand von Cluster-Analysen, Assoziationsregeln und einer Evaluierung des Überlebens von Patienten mit Ösophaguskarzinom $(E C)$, die mit CHM behandelt wurden. Patienten und Methoden: 59 Patienten mit EC, die 176 Rezepte erhielten, die 178 Kräuterarten umfassten, waren in diese Studie eingeschlossen. Die Kräuterpaare wurden sowohl durch Cluster-Analyse als auch durch Assoziationsregeln bestimmt. Das Gesamtüberleben (OS) wurde durch die Kaplan-Meier-Methode geschätzt. Ergebnisse: Acht Kräuterpaargruppen wurden durch die ClusterAnalyse identifiziert und 4 Kräuterpaargruppen wurden durch Assoziationsregeln bestimmt. Von diesen wurden 3 Kräuterpaargruppen durch beide Methoden erkannt. Die OS-Abschätzung zeigte, dass das Paar bestehend aus Hühnerkaumagen-Membran (chicken gizzardmembrane)/Astragalus mit einem verlängerten Überleben bei Patienten mit EC, die mit CHM behandelt wurden, assoziiert war. Schlussfolgerung: Patienten, die Rezepte erhielten, die das Paar bestehend aus Hühnerkaumagen-Membran und Astragalus enthielten, zeigten ein verlängertes Überleben im Vergleich zu Patienten, die Rezepte ohne dieses Paar erhielten.

\section{KARGER}

Fax +497614520714

๑ 2017 The Author(s)
Published by S. Karger GmbH, Freiburg
Open ciccess

This article is licensed under the Creative Commons AttributionNonCommercial-NoDerivatives 4.0 International License (CC BY-NCND 4.0) (http://www.karger.com/Services/OpenAccessLicense). Usage distribution for commercial purposes as well as any distribution of modified material requires written permission.

\author{
Jiali Li \\ Department of Oncology \\ Tianjin Union Medical Center \\ No. 190 Jieyuan Road, Hongqiao District, Tianjin 300121, China
}

jiajia_437@126.com 


\section{Introduction}

Esophageal cancer (EC) is one of the most common cancers worldwide, causing cancer-related deaths in approximately 15 million people annually [1]. Squamous cell carcinoma and adenocarcinoma are the 2 main histological types of EC, with squamous cell carcinoma accounting for $90 \%$ of cases [2]. Early-stage EC is asymptomatic and may not be detected or diagnosed until after the cancer has already progressed to a more advanced stage. Advanced EC has a high malignant potential and poor prognosis $[3,4]$. EC is generally treated with a combination of surgery, radiotherapy, and chemotherapy. However, the side effects of these therapies can be severe, resulting in poor patient compliance, discontinuation of therapy, and inadequate outcomes [5]. Therefore, improved treatment options are needed to achieve better clinical outcomes in patients with EC [6].

Chinese herbal medicine (CHM) has been used for centuries for the treatment of various ailments in China and is believed to be beneficial to patients [7]. Many studies have examined the individual components responsible for the anticancer activities of various herbs, and these components have been shown to dramatically affect the survival of cancer cells and/or to enhance the patient's immunity when used as the sole cancer therapy [8]. Moreover, when $\mathrm{CHM}$ is combined with surgery, radiotherapy, and chemotherapy in cancer treatment, these treatment modalities often exhibit increased efficacy and reduced side effects. Thus, CHM has been widely used as complementary and alternative medicine in the comprehensive treatment of cancer [9].

Chinese medicine formulas are usually composed of several herbs. While specific combinations of herbs may form important building blocks of a formula, formulas are usually composed in a hierarchical way including a chief ingredient, one or several deputy ingredients, and, if appropriate, assistant and envoy ingredients. The chief ingredient herb is the core of the prescription, and deputy ingredient herbs are used to enhance the efficacy or reduce the toxicity for the chief ingredient herb. For treatment of a certain disease, a few chief ingredient and deputy ingredient herbs are used closely to form a fixed combination, named herb pair. Being the classic concepts in the field of CHM, herb pairs are usually regarded as the basic unit on which the prescription laws are based [10-12]. So, determination of the herb pairs in CHM prescriptions is crucial for the treatment of EC. Another reason why herb pairs are in the focus is that formulas of CHM prescriptions are composed individually, according to the patient's specific conditions. Given this context, such an analysis needs to be introduced in the context of how formulas are prepared by Chinese medicine (CM) doctors and needs also to be discussed against the backdrop of herb use within CM in general. Unfortunately, all these details are based on a doctor's experiences, the so-called laws governing prescriptions, rather than on fixed rules. Standard medical evaluation criteria are not suitable for the investigation of herb pairs. Instead, studies applying the data mining techniques of cluster analysis and association rules have been used to mine data of herbs prescribed for cancer treatment, along with the standard method of overall sur- vival (OS) analysis $[13,14]$. Therefore, the aim of this study was to mine herb pairs in CHM prescriptions for the treatment of EC using cluster analysis and association rules and, using OS evaluation, to determine which herb pairs are beneficial to OS.

\section{Patients and Methods}

\section{Database of Patients}

In this study, we used the DBMS7.0 database for mining of prescriptions for patients treated with CHM. This database, which has been available via Microsoft Access 2010 since January 1, 2010, is a clinical oncology database management system that is used for the evaluation of clinical benefits in patients undergoing cancer treatments. The medical data stored in DBMS7.0 are renewed every 3 months [15]. As of December 31, 2014, a total of 20,889 medical records, 60 tumor types, 100,000 pathology records, 300,000 laboratory test results, 40,000 radiological examination results, 4,000 survival follow-up cases, and 41,000 cases used have been deposited in DBMS7.0 [16] .

Importantly, DBMS7.0 is linked to the Electronic Medical Records Management System (EMR), the Laboratory Information Management System (LIS), the Picture Archiving and Communication System (PACS), the database of pathology, and the database of follow-up [17]. We collected medical data from patients admitted to corresponding departments of our hospital and processed the data through preconditioning, filtering, rechecking, and excluding [18]. The data were then imported into DBMS7.0 [19]. These medical data were then used for retrospective chart reviews, statistical analyses, and data mining. Notably, results analyzed using DBMS7.0 may not demonstrate a close cause-andeffect relationship, owing to the characteristics of open-label, single-institute, non-randomized, and retrospective studies $[20,21]$.

\section{Patients}

Patients were enrolled between January 4, 2011 and December 5, 2014, and data were exported from DBMS7.0. Patients with a disease diagnosis of EC (International Classification of Diseases 10 (ICD-10) coding: C15.901) as the discharge diagnosis were included whereas patients who received radiotherapy or chemotherapy within 1 month of enrolment were excluded. Prescriptions of $\mathrm{CHM}$ given to the enrolled patients were collected and herbs in the prescriptions were processed according to standardized naming, as described in the Chinese Pharmacopoeia 2010.

\section{Law of Zipf}

The cumulative frequency $r$ was calculated according to the formula $\mathrm{R}=$ $(\ln \mathrm{r}+\mathrm{E}) /(\ln \mathrm{N}+\mathrm{E})$, based on the law of Zipf $(\mathrm{R}=90 \%, \mathrm{E}=0.5772, \mathrm{~N}=4,144)$, where $\mathrm{R}$ is the information retained for all herbs, $\mathrm{E}$ is the Euler constant, and $\mathrm{N}$ is the total frequency of herbs. From this law, the cumulative frequency $\mathrm{r}$ was 1,700 , and the utilization rate was $41.02 \%$. Consequently, $90 \%$ of the information on all herbs prescribed to the patients enrolled in this study could be represented by the top 20 herbs in terms of frequency.

\section{Frequency Analysis}

The frequencies of herbs were calculated using the Frequency option in the Descriptive Statistics tab in the SPSS 22.0 software. The results of the top 20 herbs in terms of frequency were exported according to the degree of frequency from high to low.

\section{Cluster Analysis}

Data on the top 20 herbs in terms of frequency were imported into the cluster analysis form, which was established in Microsoft Office Excel 2013, and subjected to data cleaning. Each herb in a prescription was assigned a score of 0 or 1, indicating 'present' or 'absent', respectively. The herb pairs were defined as the smallest cluster groups containing only 2 herbs with each herb in its first stage of clustering. The herbs underwent the process of cluster analysis using SPSS 22.0 and the results were exported according to the degree of the coefficient factor from low to high. 
Association Rules

To mine out herb pairs from the prescriptions, all herbs were analyzed by association rules using Weka3.6.12 with a minimum support (ms) of 0.35 and a minimum confidence $(\mathrm{mc})$ of 0.7 . Results of 2-herb associations were identified and exported according to the degree of confidence from high to low. Bidirectional associations were defined as having both associations from left to right and from right to left; these were considered as associated herb pairs. In contrast, unidirectional associations were defined as having one association either from left to right or from right to left; this was considered a calculation error of the association rules in herb pair mining of CHM.

\section{OS Estimation}

Mined herb pairs were identified as the herb pairs analyzed by both cluster analysis and association rules owing to their close relationships. Patients who received prescriptions containing the mined herb pairs were included in the experimental group, and patients who received prescriptions lacking the mined herbs were included in the corresponding control group. Patients in both groups were followed up from January 1, 2011 to December 31, 2014. OS was the duration from the date of enrolment to the date of death. Patients were con-

Table 1. Frequency analysis of herbs included in CHM prescriptions given to patients with EC $(\mathrm{N}=176)$

\begin{tabular}{rlll}
\hline No. & Herb & $\mathrm{N}$ & $\%$ \\
\hline 1 & chicken gizzard-membrane & 119 & 67.61 \\
2 & Astragalus & 116 & 65.91 \\
3 & Atractylodes & 109 & 61.93 \\
4 & Schisandra & 100 & 56.82 \\
5 & prepared liquorice root & 97 & 55.11 \\
6 & Poria & 95 & 53.98 \\
7 & root of herbaceous peony & 94 & 53.41 \\
8 & turmeric & 93 & 52.84 \\
9 & Prunella & 85 & 48.30 \\
10 & Hedyotis diffusa & 85 & 48.30 \\
11 & Rehmannia & 76 & 43.18 \\
12 & Codonopsis & 75 & 42.61 \\
13 & Ligustrum & 75 & 42.61 \\
14 & barbed skullcap herb & 74 & 42.05 \\
15 & Magnolia & 72 & 40.91 \\
16 & piece of turmeric & 69 & 39.20 \\
17 & Amomum & 63 & 35.80 \\
18 & raw oysters & 61 & 34.66 \\
19 & calcined ocher & 61 & 34.66 \\
20 & Citrus aurantium & 60 & 34.09 \\
\hline & & &
\end{tabular}

sidered to have died when the date of death could be determined. Patients were considered to have 'survived' when they were still alive at the end of the followup period or were lost to follow-up, when their survival status was unknown, or when the date of death could not be determined.

\section{Statistical Analysis}

Data were analyzed with the Kaplan-Meier method for estimation of OS curves using SPSS 22.0 software. Differences or associations with P values of less than 0.05 were considered statistically significant.

\section{Results}

\section{Frequency Analysis}

There were 59 patients enrolled in this study ( 45 men, 14 women; average age: $68.13 \pm 12.62$ years, range: $38-89$ years); of these patients, 42 'survived' while 17 died, yielding a 'survival' rate of $71.19 \%$. The frequency of prescribed herbs in total was 4,144 , with 178 different types of herbs from 176 prescriptions. The top 8 herbs based on frequency were chicken gizzard-membrane, Astragalus, Atractylodes, Schisandra, prepared liquorice root, Poria, root of herbaceous peony, and turmeric (table 1).

\section{Cluster Analysis}

After 19 stages of clustering, there were 8 groups of clustered herb pairs identified by cluster analysis, including Magnolia/calcined ocher, Atractylodes/Poria, Hedyotis diffusa/barbed skullcap herb, Angelica/root of herbaceous peony, Codonopsis/raw oysters, prepared liquorice root/turmeric, Schisandra/Ligustrum, and chicken gizzard-membrane/Astragalus (table 2 and fig. 1).

\section{Association Rules}

There were 4 groups of herb pairs identified by association rules, including Angelica/root of herbaceous peony, Atractylodes/ Poria, chicken gizzard-membrane/Astragalus, and Angelica/Poria (table 3).

\section{OS Estimation}

There were 3 groups of herb pairs that were identified by both cluster analysis and association rules, including Angelica/root of herbaceous peony, Atractylodes/Poria, and chicken gizzard-

Table 2. Cluster analysis of herbs in CHM prescriptions given to patients with $\mathrm{EC}(\mathrm{r}=2,205)$

\begin{tabular}{|c|c|c|c|c|c|c|}
\hline \multicolumn{7}{|c|}{ Agglomeration schedule } \\
\hline \multirow[t]{2}{*}{ Stage } & \multicolumn{2}{|l|}{ Cluster combined } & \multirow[t]{2}{*}{ Coefficient } & \multicolumn{2}{|c|}{ Stage at which cluster first appears } & \multirow[t]{2}{*}{ Next stage } \\
\hline & Cluster 1 & Cluster 2 & & Cluster 1 & Cluster 2 & \\
\hline 1 & Magnolia & calcined ocher & 23.000 & 0 & 0 & 18 \\
\hline 2 & Atractylodes & Poria & 30.000 & 0 & 0 & 9 \\
\hline 3 & Hedyotis diffusa & barbed skullcap herb & 31.000 & 0 & 0 & 5 \\
\hline 4 & Angelica & root of herbaceous peony & 33.000 & 0 & 0 & 9 \\
\hline 6 & Codonopsis & raw oysters & 44.000 & 0 & 0 & 14 \\
\hline 7 & prepared liquorice root & turmeric & 44.000 & 0 & 0 & 8 \\
\hline 10 & Schisandra & Ligustrum & 49.000 & 0 & 0 & 13 \\
\hline 11 & chicken gizzard-membrane & Astragalus & 49.000 & 0 & 0 & 15 \\
\hline
\end{tabular}


Fig. 1. Pedigree chart of cluster analysis for herbs found in CHM prescriptions given to patients with EC.

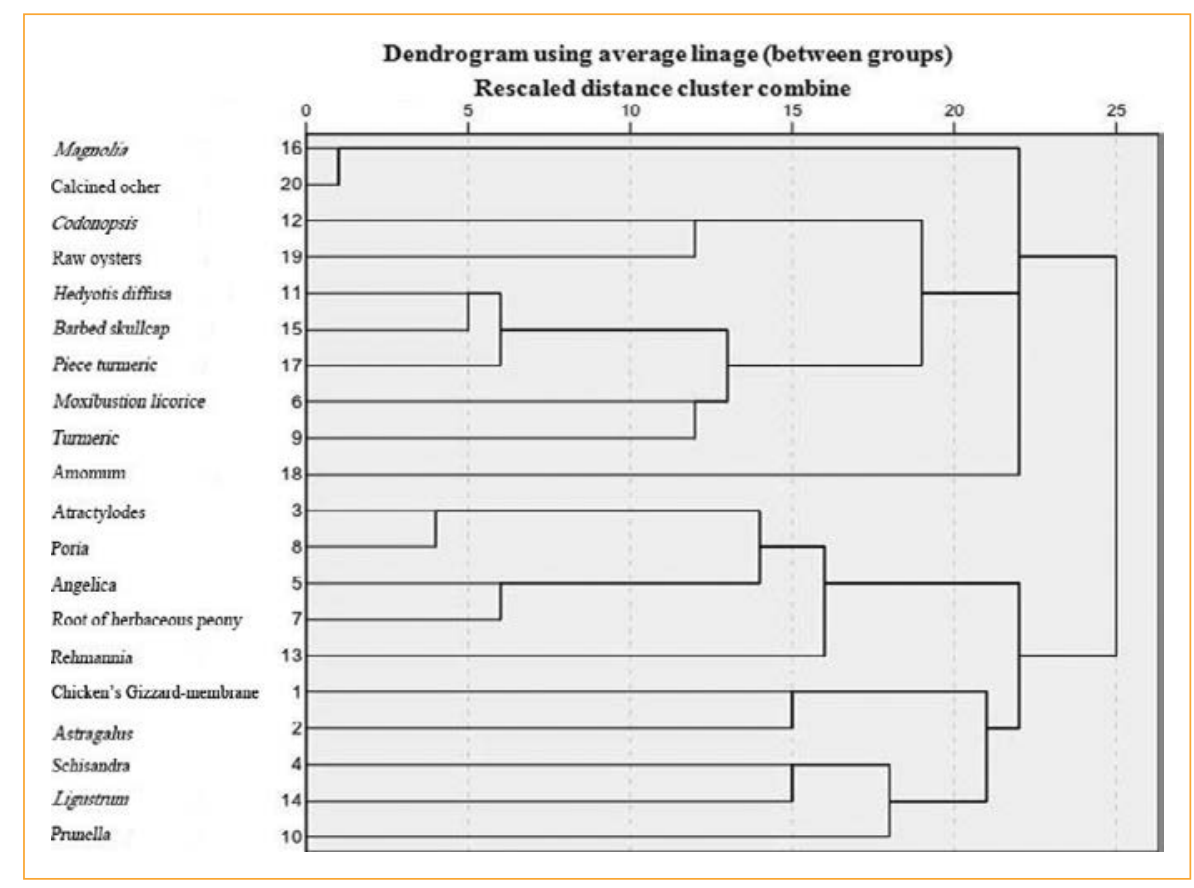

\begin{tabular}{lllll}
\hline No. & Herb 1 & Herb 2 & N ms, \% & $\mathrm{mc} \%$ \\
\hline 1 & Angelica & root of herbaceous peony & 970.54 & 0.81 \\
2 & Atractylodes & Poria & 870.49 & 0.80 \\
3 & chicken gizzard-membrane & Astragalus & 930.52 & 0.78 \\
4 & Angelica & Poria & 970.54 & 0.78 \\
\hline
\end{tabular}

$\mathrm{ms}=$ minimum support $\mathrm{mc}=$ minimum confidence; $\mathrm{N}=$ number of prescriptions.
Table 3. Association rules for herbs in $\mathrm{CHM}$ prescriptions given to patients with $\mathrm{EC}(\mathrm{ms}=0.35$, $\mathrm{mc}=0.7)$
Table 4. Herb pairs providing survival benefits in patients with EC prescribed CHM $(\mathrm{N}=59$ cases $)$

\begin{tabular}{llllll}
\hline No. & Herb 1 & Herb 2 & Survival rate, \% & P value \\
\cline { 4 - 5 } & & Experimental group & Control group & \\
\hline 1 & Angelica & root of herbaceous peony & $60.0(18 / 30)$ & $82.8(24 / 29)$ & 0.175 \\
2 & Atractylodes & Poria & $65.7(23 / 35)$ & $79.2(19 / 24)$ & 0.480 \\
3 & chicken gizzard-membrane & Astragalus & $87.0(20 / 23)$ & $66.7(24 / 36)$ & 0.046 \\
\hline
\end{tabular}

membrane/Astragalus (table 4). The 'survival' rate was $87.0 \%$ in the 23 patients who received prescriptions containing chicken gizzard-membrane/Astragalus in the experimental group, but only $66.7 \%$ in the 36 patients who received prescriptions lacking chicken gizzard-membrane/Astragalus in the control group. There were significant differences in OS between the 2 groups $(\mathrm{P}=$ 0.046). Therefore, the herb pair of chicken gizzardmembrane/Astragalus was found to be associated with improved OS in patients with EC receiving CHM (table 4 and fig. 2). There were no significant differences in OS between the experimental group and the corresponding control groups for the herb pairs of Angelica/root of herbaceous peony and Poria/Codonopsis ( $60.0 \%$ vs. $82.8 \%$, respectively; $\mathrm{P}=0.175)$ and Atractylodes/Poria and Schisandra/Ligustrum (65.7\% vs. $79.2 \%$, respectively; $\mathrm{P}=$ 0.480; table 4 and fig. 2).

\section{Discussion}

In this study, we aimed to identify herb pairs associated with improved OS administered as components in $\mathrm{CHM}$ to patients with EC $[22,23]$. So, the data mining techniques of cluster analysis and association rules and the standard method of OS analysis were used together. Data mining is the process of extracting the relevant laws from a large number of random and fuzzy data, wherein the association rules and clustering analysis are 2 important data mining methods used in the field of CHM research applications. The association rules reflect a certain regularity existing between 2 or more variables, such as 'object A occurs simultaneously with object B' or 'object A can be introduced from object B', etc. Support and confidence are 2 important metrics in the association rules. For herb A and herb B involved in all prescriptions for the treatment of a particular disease, such as EC, support represents the probability 
Fig. 2. OS curves in patients with EC who received prescriptions containing chicken gizzardmembrane and Astragalus $(\mathrm{P}=0.046)$.

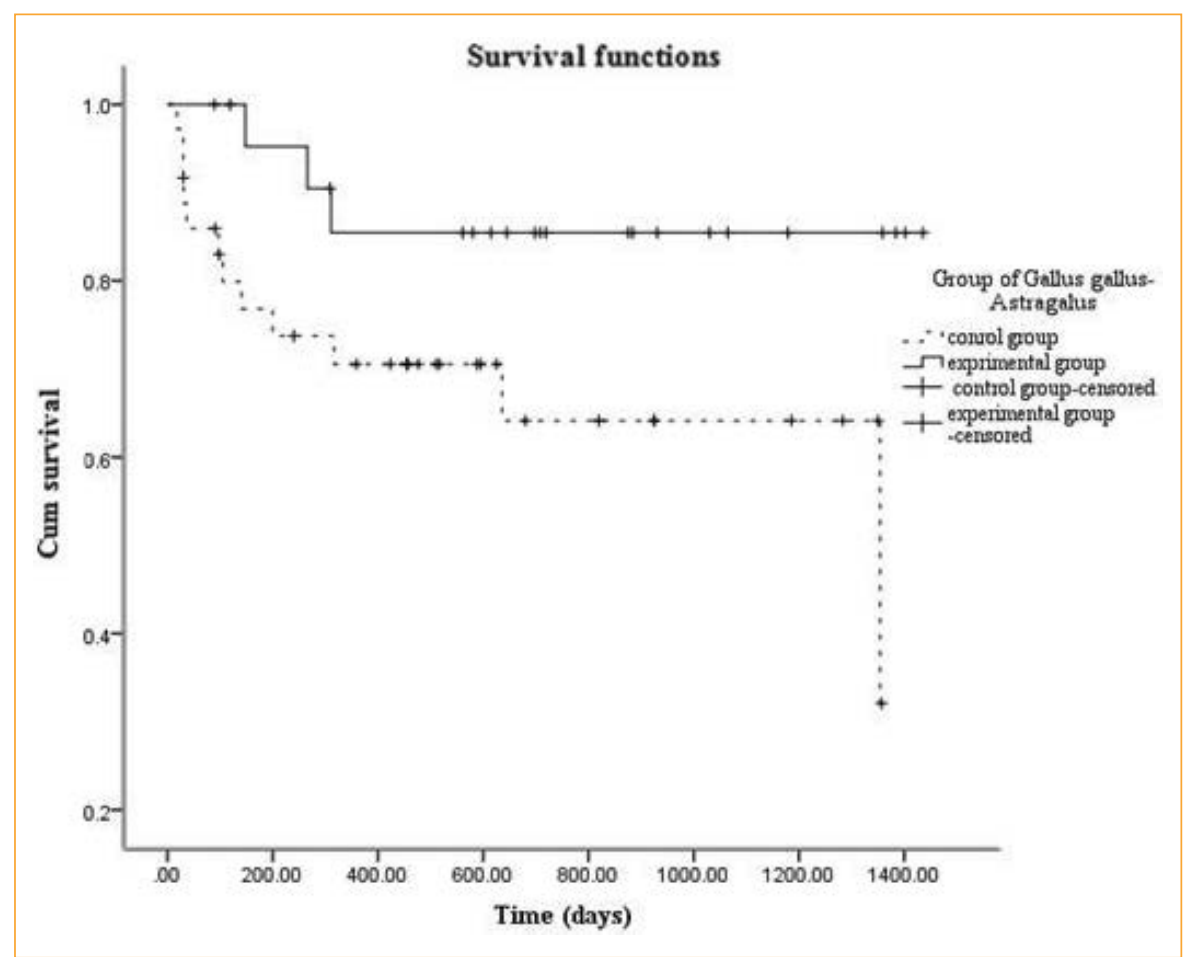

that herb A and herb B simultaneously appear in a prescription, and confidence indicates the probability of herb B appearing when herb A exists in the same prescription. Cluster analysis is also a mathematical analysis method used to classify data so that samples with a common characteristic will gather into the same group. Data in the same cluster group tend to have a more close intrinsic relationship to each other, and data in different cluster groups tend to be less similar to each other. According to the inherent degree of pharmaceutical similarity or closeness of combined usage, herbs in the prescriptions can be classified into associated or clustered herbs pairs. The combination pairs assigned a priori may be composed of 2 herbs or more. Actually, the information of a triple (or more) herb combination can be represented by several double herb combinations. The same thing happens in cluster analysis. So, only double combinations are in the focus of this paper.

How formulas are prepared (herbs in a formula depend on the knowledge and experience of the doctor and on the patient as an individual) has always been a research focus in CHM, and it is still based on empirical analysis rather than on objective evidence, i.e. it is greatly influenced by subjective factors. The special term of herb pairs may play a key role to resolve the problem; herb pairs are the basic unit on which the prescription laws are based and are easily mined by artificially separating results from the context within which the analyzed data were generated.

Our results identified 8 groups of herb pairs from cluster analysis and 4 groups of herb pairs from association rules. Of these, 3 herb pairs were identified by both methods, including Angelical root of herbaceous peony, Atractylodes/Poria, and chicken gizzardmembrane/Astragalus. The identification of herb pairs by cluster analysis and association rules is associated with mathematical bias, which can be ruled out by survival, a standard endpoint used to evaluate the benefits of cancer treatment $[24,25]$. Therefore, we further filtered our mined data based on OS estimation. From this analysis, we identified the herb pair of chicken gizzardmembrane/Astragalus as an OS-promoting herb pair in CHM. Indeed, patients who received prescriptions containing chicken gizzard-membrane/Astragalus were found to have longer OS than patients who received prescriptions lacking chicken gizzardmembrane/Astragalus. In this study, data mining of herb pairs that promote OS by cluster analysis, association rules, and OS estimation was used to focus on patterns in terms of 'herb pairs' found among prescriptions used for EC patients, which might reflect on prescription laws (a prescription law is what the doctors rely on) to some extent. These data were obtained from empirical evidence collected from DBMS7.0. Therefore, this combined data mining technique may provide insights into the herb pairs in cancer treatment, and data mining tools could also facilitate further analyses of the efficacy of CHM, supporting the clinical applications of CHM.

It is believed that more data is needed from studies on CHM instead of the experiences of doctors. This is our first preliminary attempt to analyze the formulas of CHM with the combined use of the methods of cluster analysis, association rules, and OS estimation. Notably, it is important to emphasize that the methods applied in this study, i.e. cluster analysis and association rules, cannot be used alone to resolve the shortcomings of CHM research. In this study, the mentioning of an experimental group or a control group may be misleading. It could be that one more herb beside the pair might be driving the results. It is possible that certain herbs (and pairs) have been assigned due to symptomatology. Certain symptoms, however, might be a direct factor for OS. So, combined analysis using mathematics and medical expertise should be applied, and more clinical data should be collected to be analyzed in detail. 


\section{Conclusion}

In conclusion, our results show that OS could be prolonged in patients with EC who received prescriptions containing the herb pairs of chicken gizzard-membrane/Astragalus. The combination of cluster analysis, association rules, and OS evaluation may be useful for investigating the laws of $\mathrm{CHM}$, providing support for $\mathrm{CHM}$ through evidence-based medicine.

\section{Acknowledgement}

This study was supported by Tianjin Science and Technology Project (2015069) from Tianjin Traditional Chinese Medicine Administration.

项目基金 : 天津市中医药管理局. 中药方剂大数据分析平台建立及其初 步应用. 天津市科技计划项目 (2015069).

\section{Disclosure Statement}

There are no conflicts of interest to declare.

\section{References}

1 Gong J, Huang Z, Huo JR: Involvement of F-box proteins in esophageal cancer (Review). Int J Oncology 2016;48:886-894.

2 Han N, Zhao W, Zhang Z, Zheng P: MiR-328 suppresses the survival of esophageal cancer cells by targeting PLCE1. Biochem Biophys Res Commun 2016;470: 175- 180 .

3 Njei B, McCarty TR, Birk JW: Trends in esophageal cancer survival in United States adults from 1973 to 2009: a SEER database analysis. J Gastroenterol Hepatol 2016;31:1141-1146.

4 Petrick JL, Nguyen T, Cook MB: Temporal trends of esophageal disorders by age in the Cerner Health Facts database. Ann Epidemiol 2016;26:151-4.e1-4.

5 Meng MB, Zaorsky NG, Jiang C, et al: Radiotherapy and chemotherapy are associated with improved outcomes over surgery and chemotherapy in the management of limited-stage small cell esophageal carcinoma. Radiother Oncol 2013;106:317-322.

6 Berger B, Stahlberg K, Lemminger A, et al: Impact of radiotherapy, chemotherapy and surgery in multimodal treatment of locally advanced esophageal cancer. Oncology 2011;81:387-394.

7 Chung V, Wu X, Hui EP, Ziea ET, Ng BF, Ho RS, et al: Effectiveness of Chinese herbal medicine for cancer palliative care: overview of systematic reviews with meta-analyses. Sci Rep 2015;5:18111.

8 Kuo CC, Chen JJ, Tsai JY, Hsueh CT: Effects of Chinese herbal medicine in combination with mitomycin $\mathrm{C}$ on gastric cancer cells. Biomarker Res 2014;2:26.

$\checkmark$ Li B, Gan R, Yang Q, Huang J, Chen P, Wan L, et al: Chinese herbal medicines as an adjunctive therapy for unresectable pancreatic cancer: a systematic review and meta-analysis. Evid Based Complement Alternat Med 2015;2015:350730.
10 Deng S, Li J, Luo L: Herbal medicine on modern research progress. Lishizhen Med Mater Med Res 2012; 23:4.

11 Wang S, Hu Y, Chen R, Zhong Z, Chen M, Wang Y: Herbal medicine on the system research (II) - efficacy and pharmacokinetic studies. World Sci Technol/Modern of Tradit Chin Med Mater Med 2012;14:2.

12 Wang J, Li S, Li M: Herbal medicine to the modern understanding and research. J Tradit Chin Med 2016;57:8.

13 Jia Y, Du H, Yao M, Cui X, Shi Q, Wang Y, et al: Chinese herbal medicine for myelosuppression induced by chemotherapy or radiotherapy: a systematic review of randomized controlled trials. Evid Based Complement Alternat Med 2015;2015:690976.

14 Chen G, Qiao TT, Ding H, Li CX, Zheng HL, Chen XL, et al: Use of Chinese herbal medicine therapies in comprehensive hospitals in Central China: a parallel survey in cancer patients and clinicians. Huazhong keji daxue xuebao Yixue Yingdewen ban 2015;35:808-814.

15 Yu S, Fung G, Dehing-Oberije C, et al: Modeling lung cancer survival probability after or side-effects from therapy. US Patent 8032308 B2, 2011.

16 Crabtree TD, Kosinski AS, Varun P, et al: Evaluation of the reliability of clinical staging of T2 N0 esophageal cancer: a review of the Society of Thoracic Surgeons database. Ann Thorac Surg 2013;96:382-390.

17 Qingguo L, Guoxiang C, Dawei L, et al: Better longterm survival in young patients with non-metastatic colorectal cancer after surgery, an analysis of 69,835 patients in SEER database. PLoS One 2014;9:e93756.
18 Gohlke BO, Nickel J, Otto R, et al: CancerResource updated database of cancer-relevant proteins, mutations and interacting drugs. Nucleic Acids Res 2015; 44:D932-D937.

19 Kumar R, Chaudhary K, Gupta S, et al: CancerDR: cancer drug resistance database. Sci Rep 2013;3:1445.

20 Kim P, Cheng F, Zhao J, et al: ccmGDB: a database for cancer cell metabolism genes. Nucleic Acids Res 2015; 44:D959-D968.

21 Abbott KL, Nyre ET, Juan A, et al: The Candidate Cancer Gene Database: a database of cancer driver genes from forward genetic screens in mice. Nucleic Acids Res 2015:43:D844-D848.

22 Yanan M, Xiaohui L, Xiongzhi W: Chinese medicine herbal treatment based on syndrome differentiation improves the overall survival of patients with unresectable hepatocellular carcinoma. Chin J Integr Med 2015; 21:49-57.

23 Xun L, Xiaoshu Z, Jun R, et al: Impact of Chinese herbal medicine on survival, relapse and metastasis in women with breast cancer: a systematic review of randomized controlled trial. J Altern Complement Med 2014;20:A62.

24 Zhang Y, Ming-Wei YU, Wang XM, et al: Study on the prescription-herb's rules of lung cancer based on factor and cluster analysis in the ancient literatures. China J Tradit Chin Med Pharm 2013;12:296-298.

25 Zhang L, Zhu W, Li J, et al.: Clinical outcomes of immunotherapy with dendritic cell vaccine and cytokineinduced killer cell therapy in hepatobiliary and pancreatic cancers. Mol Clin Oncol 2015;4:129-133. 